\title{
Benefit and danger from immunotherapy in myasthenia gravis
}

\author{
Carmelo Rodolico $^{1}$ (ID $\cdot$ Giulia Nicocia ${ }^{1} \cdot$ Valentina Damato $^{2} \cdot$ Giovanni Antonini $^{3} \cdot$ Rocco Liguori $^{4,5} \cdot$ Amelia Evoli $^{2}$
}

Received: 19 November 2020 / Accepted: 18 January 2021 / Published online: 5 February 2021

(C) Fondazione Società Italiana di Neurologia 2021

\begin{abstract}
In the last years, significant advances have improved the knowledge of myasthenia gravis (MG) immunopathogenesis and have enabled to realize new molecules with a selective action targeting compounds of the immunological system. This review discusses emerging treatments for MG, including complement inhibitors, neonatal Fc receptor targeting agents, and B cell interfering drugs, focusing on benefit and danger. In the second section of the review, several related adverse events of immunotherapy, including MGonset, are debated.
\end{abstract}

Keywords Refractory myasthenia gravis $\cdot$ Emerging therapy $\cdot$ Immunotherapy $\cdot$ Checkpoint inhibitors

\section{Introduction}

Myasthenia gravis (MG) is an autoimmune disease caused by autoantibodies targeting neuromuscular junction (NMJ) components as the acetylcholine receptor (AChR), musclespecific kinase (MuSK), and lipoprotein-related peptide 4 (LRP4). Therapeutic strategies are intended to achieve an adequate control of disease minimizing the adverse events [1] and they include pyridostigmine, corticosteroids, and immunosuppressants (i.e., azathioprine, mycophenolate mofetil). Depletion or neutralization of serum autoantibodies by plasma exchange (PLEX) or intravenous immunoglobulins (IVIg) is useful in myasthenic crisis and disease exacerbations [1]. Long-term conventional immunosuppressants may be associated with the risk of intolerance, delayed onset of action, and

Carmelo Rodolico

crodolico@unime.it

1 Department of Clinical and Experimental Medicine, Unit of Neurology and Neuromuscular Diseases, University of Messina, Messina, Italy

2 Department of Neurosciences, Catholic University, Rome, Italy

3 Department of Neuroscience, Mental Health and Sensory Organs (NESMOS), Sant'Andrea Hospital, Sapienza University of Rome, Rome, Italy

4 Department of Biomedical and Neuromotor Sciences, University of Bologna, Bologna, Italy

5 IRCCS, Institute of Neurological Sciences, Bologna, Italy systemic toxicity. One third of patients can be affected by "refractory MG" [2].

In the last years, significant advances have been reached in MG therapy. Improved knowledge of MG immunopathogenesis has enabled to realize new molecules, some of them already used in other autoimmune and neoplastic diseases, targeting compounds of the immunological system as B cells, proinflammatory cytokines, and their receptors, complement system, and Fc neonatal receptor $(\mathrm{FcRn})$ [3-7]. Moreover, several biological targeting therapies for other immune-related disorders have been associated with the worsening or the onset of $\mathrm{MG}$ [8-10]. Most recently, immunotherapy for cancer by checkpoint inhibitors, which break off the immune system blocking cytotoxic $\mathrm{T}$ lymphocyte-associated protein 4 (CTLA-4) and programmed cell death protein 1 (PD-1) binding to their receptors, has been associated with several immune-related adverse events including MG onset [11]. The present review is focused on the benefit and danger of the emerging therapy for $\mathrm{MG}$ and on possible related effects caused by immunotherapy.

\section{Complement inhibitors}

Considering that complement cascade has an important role in MG pathogenesis linked to IgG1 antibodies (Abs) against $\mathrm{AChR}$, the benefit of complement inhibitors in MG treatment has been proved [12]. Eculizumab is a humanized recombinant monoclonal antibody that, binding to $\mathrm{C} 5$ fragment, prevents its cleavage, formation of complement terminal complex [membrane attack complex (MAC)], and subsequent NMJ damage [13]. The US Food and Drug Administration (FDA) 
approved eculizumab for the treatment of paroxysmal nocturnal hemoglobinuria [PNH] (2007), atypical hemolytic uremic syndrome [aHUS] (2011), neuromyelitis optica spectrum disorder [NMOSD] (2020) [3-5], and AChR Abs+ generalized MG (gMG) [14].

It was also approved for refractory AChR Abs $+\mathrm{gMG}$ in Europe [15]. Efficacy, safety, and tolerability had been clearly proved in phase 3 (REGAIN study, induction dose of $900 \mathrm{mg} /$ week for 4 doses followed by a maintenance dose of $1200 \mathrm{mg}$ at week 4 and then every 2 weeks) and in an open-label extension (OLE study, a dose of $1200 \mathrm{mg}$ at week 4, and then every 2 weeks) clinical trials [16, 17].

Neisseria meningitides vaccination at least 2 weeks prior to the first dose of eculizumab is required [16, 17]. Other adverse events include headache and nasopharyngitis [16, 17]. Ravulizumab is an intravenous humanized monoclonal $\mathrm{Ab}$ high-affinity $\mathrm{C} 5$ inhibitor, with a half-life longer than eculizumab. FDA-approved ravulizumab for PNH and aHUS treatment after clinical trials in which it was effective like eculizumab but with a reduced frequency of administration (every 8 weeks instead of 2 weeks) [18]. A phase 3 clinical trial in refractory MG is ongoing. Zilucoplan is a small peptide that blocks the cleavage of $\mathrm{C} 5$. A randomized, doubleblind, placebo-controlled, phase 2 study was conducted in 44 patients affected by AChR Ab+ gMG to evaluate subcutaneous (SC) zilucoplan clinical effect [19]. The patients treated with zilucoplan $0.3 \mathrm{mg} / \mathrm{kg}$ daily for 12 weeks showed a statistically significant improvement in primary and secondary endpoints compared with the placebo group. Zilucoplan showed a favorable safety profile with minor side effects and without meningococcal infection. The phase 3 study to confirm the safety and efficacy of zilucoplan in gMG is ongoing.

\section{Neonatal fc receptor antagonists}

FcRn, expressed on endothelial cells, prolongs half-life of serum albumin and $\mathrm{IgG}$ by their recycling. IgG and albumin are bound by $\mathrm{FcRn}$ with a high affinity at endosomal acidic $\mathrm{pH}$ (5.0-6.5). Then, avoiding lysosomal degradation, they are released across a cellular surface at neutral $\mathrm{pH}$ of 7.4 [20]. FcRn inhibitors reduce IgG plasma levels, blocking their recycling and increasing their clearance. FcRn inhibition could be a promising therapeutic option in $\mathrm{AChR} \mathrm{Ab+} \mathrm{and}$ MuSK Ab+ MG.

Efgartigimod is an engineering human IgG1-derived $\mathrm{Fc}$ fragment. Considering the similar FcRn-binding features of human and cynomolgus monkey IgG, the effect of efgartigimod on serum levels IgG-depleting was found in this animal species and in human healthy volunteers [21]. In phase 2 , randomized at ratio $1: 1$, trial on $24 \mathrm{AChR} \mathrm{Ab}+$ gMG patients, a rapid and sustained decrease of IgG (70.7\%) and AChR Ab serum levels (40-70\%) was seen in the efgartigimod group compared with the placebo group. Simultaneously, a significant clinical improvement emerged in quantitative myasthenia gravis (QMG), Myasthenia gravis activities of daily living profile (MGADL), Myasthenia Gravis Composite (MGC), and Myasthenia Gravis Quality of Life 15-item (MG-QoL15r) scales [22]. Efgartigimod was well tolerated. The most frequent treatment-emergent adverse events (TEAEs) were headache and reduction of monocyte count [22]. A phase 3 clinical trial is currently underway [23].

Rozanolixizumab is a high affinity humanized monoclonal IgG4P Ab direct against FcRn taking the advantage of SC administration. In phase 2, placebo-controlled study, 43 severe $\mathrm{AChR} \mathrm{Ab}+$ and MuSK $\mathrm{Ab}+\mathrm{gMG}$ patients were randomized to receive $\mathrm{SC} 7 \mathrm{mg} / \mathrm{kg}$ rozanolixizumab or placebo, and after 4 weeks, they were re-randomized to 3 weekly doses of either 4 or $7 \mathrm{mg} / \mathrm{kg}$ [24]. The QMG, MG-ADL, and MGC responder rates were $38.1 \%, 47.6 \%$, and $47.6 \%$, respectively, for the rozanolixizumab group compared to $22.7 \%, 13.6 \%$, and $27.3 \%$, respectively, for the placebo group. $\operatorname{IgG}$ and $\mathrm{AChR} A \mathrm{Ab}+$ titers decreased by $68 \%$ from baseline 24 . Headache was the most common side effect. A phase 3 study is ongoing.

Nipocalimab (M281) is a human de-glycosylated IgG1 monoclonal antibody with a high affinity to FcRn. In a phase 1 study, 50 healthy volunteers were organized in SAD (single ascending doses) cohort $(n=34)$, treated with doses of 0.3-310-30-60 mg/kg (24 with M281, 10 with placebo), and MAD (multiple-ascending doses) cohort ( $n=16)$ receiving 4 weekly $15 \mathrm{mg} / \mathrm{kg}(n=6)$ or $30 \mathrm{mg} / \mathrm{kg}(n=6)$ of M281 or placebo $(n=4)$ [25]. IgG serum reduction was M281 dose-dependent. During SAD, $74 \%$ and $80 \%$ decrease in IgG titers was observed at doses of 30 and $60 \mathrm{mg} / \mathrm{kg}$, respectively, in MAD cohort up to $\approx 85 \%$. No serious TEAEs and a low rate of infection were reported in the M281 group. Antidrug Abs were low in SAD (12\%) and in MAD (31\%) patients [25]. A phase 2 study to evaluate the safety, tolerability, and efficacy of M281 was completed in June 2020. Sixty patients with AChR+ or MuSK+ gMG were organized into 5 arms of treatment (4 with IV M281 and 1 IV placebo), and the results are still not available [26].

\section{B cell targeting agents}

B cells are the principal components of the humoral immune response. They are crucial in MG immunopathogenesis by the generation of autoantibodies and by a presentation of antigens on their surface with class II major histocompatibility complex (MHCII) inducing T cells to secrete proinflammatory cytokines [27]. B cell-activating factor (BAFF) is a factor which, binding its receptor on $\mathrm{B}$ cell surface, blocks apoptosis and induces proliferation and differentiation of B lymphocytes into plasma cells [28]. CD20 antigens are phosphoproteins 
expressed on B cell surface involving in their activation and differentiation. Monoclonal Abs direct against CD20 proteins can induce B lymphocytes depletion by their direct apoptosis or complement-dependent cytolysis or antibody-dependent cell-mediated cytotoxicity [29]. B lymphocyte depletors can act directly or indirectly.

\section{Direct B cells targeting agents}

Rituximab (RTX) is a chimeric human/mouse IgG1 monoclonal $\mathrm{Ab}$ acting against $\mathrm{CD} 20$ approved by the FDA for rheumatoid arthritis [RA], non-Hodgkin lymphoma, chronic lymphocytic leukemia, pemphigus vulgaris, granulomatosis with polyangiitis, and microscopic polyangiitis [30], and it is in offlabel prescription for refractory systemic lupus erythematosus (SLE) [6]. Data currently available show RTX effectiveness and tolerability in AChR Ab+ refractory MG, especially in MuSK Ab+ (regime more used: $375 \mathrm{mg} / \mathrm{m}^{2} /$ week four consecutive weeks and $1000 \mathrm{mg}$ on day 1 and day 15). The greatest response of RTX in MuSK Ab + patients could be explained by the major effect of the drug on IgG4-producing B cells [31, 32]. A review comparing 169 patients (59\% AChR-Ab+, 34\% MuSK-Ab+) showed that modified MGFA (Myasthenia Gravis Foundation of America) post-intervention scale of minimal manifestations (MM) or better occurred in $72 \%$ of MuSK Ab+ MG patients and in $30 \%$ of $\mathrm{AChR} \mathrm{Ab+MG}$ patients and that post-treatment relapses were less frequent in MuSK Ab+ MG [33]. In a systematic review, $165 \mathrm{AChR}$ $\mathrm{Ab}+\mathrm{MG}$ patients from 13 studies were analyzed to evaluate the best evidence for RTX in subtype AChR Ab+ MG [34]. Clinical improvement after treatment was reported in $68 \%$ of patients, and a reduction of the immunosuppressant average dose was obtained in 9 studies [34]. A recent review showed better outcomes in gMG patients treated with RTX in the early phase of disease compared with those treated 12 or more months from disease onset, and a shorter time of remission in the RTX group than in the conventional immunosuppressant group [35]. Therefore, they speculated that RTX should be considered a recommended therapy in new-onset disease. Some studies were conducted to evaluate the efficacy and safety of repeated low-dose RTX in patients with refractory MG that could be a cost-effective therapeutic option [36].

In contrast to promising data obtained from retrospective studies, in phase 2, randomized, placebo-controlled trial (BeatMG study) not statistically significant difference was found between RTX and placebo group considering corticosteroid-sparing as the primary outcome [37]. A phase 3 trial is ongoing. To date, rituximab is usually well tolerated and it can be considered a worthwhile option to treat MuSK+ Ab-related gMG [38]. In a few cases, side effects were reported, including flushing, allergic reaction, headache, fever, myocardial infarction, diabetes, and hypertension [33, 34, 38]. Immunosuppression and agranulocytosis due to $\mathrm{B}$ cell depletion occasionally lead to infections and to reactivation of herpes zoster [33, 34]. The risk of RTX-induced progressive multifocal leukoencephalopathy (PML) should not underestimated and serum determination of anti-John Cunningham virus (JCV) Abs is required prior to treatment. One case of PML-induced death has been reported [39].

Ofatumumab, obinutuzumab, and ocrelizumab are other anti-CD20 agents representing potential future therapeutic alternatives for refractory MG [40-42].

\section{Indirect B cells targeting agents}

Belimumab is a human IgG1 $\lambda$ monoclonal Ab against B lymphocyte stimulator (BLys) against BAFF and approved for SLE treatment [43]. Some studies showed that serum BAFF levels in MG patients (especially $\mathrm{AChR} \mathrm{Ab}+$ ) were higher than those of controls. BAFF seems to have a role in MG pathogenesis and, therefore, to be a potential novel therapeutic target [44]. In phase 2, randomized, placebo-controlled clinical trial, not statistically significant difference was found between belimumab and placebo group in primary efficacy endpoint (QMG score) at 24 weeks [45]. The most frequent TEAEs, in belimumab (78\%) and placebo (91\%) groups, were flu and nausea, headache, diarrhea, and back pain [45].

Bortezomib is a dipeptide that, inhibiting proteasome function, induces accumulation of misfolded or unfolded proteins in plasma cells culminating in cell death. Bortezomib, used in multiple myeloma and "mantle cell lymphoma" treatment [7], seems to be a new therapeutic approach in autoimmune diseases [46]. Promising results were achieved in a single case of severe refractory MuSK Ab + MG [47]. A phase 2 study was conducted on refractory MG, SLE, and RA patients to evaluate proteasome-inhibitor capacity to improve the clinical course of autoimmune diseases decreasing serum autoantibody [48]. Sensorimotor polyneuropathy and reactivation of herpes virus infection may be a risk (30-40\% of treated cases) for patients taking bortezomib due to its neurotoxicity [49]. Etanercept (human soluble anti-TNF fusion protein), Infliximab (chimeric human-mouse $\mathrm{Ab}$ ), and Adalimumab (humanized anti-TNF $\mathrm{Ab}$ ) are TNF (tumor necrosis factor)inhibitors (TNFis) that prevent the interaction of TNF $\alpha$ and TNF $\beta$ with cell-surface TNF receptors. TNF is a proinflammatory cytokine that plays a critical role in the pathogenesis of autoimmune diseases. Studies showed that TNF is involved in the activation of AChR-specific T and B cells in EAMG [50]. Anti-TNF agents downregulate TNF-induced inflammatory response and cause TNF $\alpha$-secreting cells lysis.

They are approved for autoimmune disease treatment such as RA. Contrasting data have been reported in the literature concerning the benefit of these drugs in MG. During longterm TNFis treatment, the risk of infection and autoimmune phenomena should not be underestimated. In a pilot study, etanercept was effective in 8/11 MG corticosteroid- 
dependent patients with a low-serum level of IL-6 (interleukin-6) and IFN- $\gamma$ (interferon- $\gamma$ ). $2 / 11$ patients with a higher level of abovementioned cytokines presented MG symptoms worsening [8]. Individual cases of MG onset/ exacerbation during concomitant treatment with anti-TNF agents have been described $[9,10]$. Therefore, careful monitoring of the treatment is required, and further immunological studies are needed to verify the TNFis safety. A valid potential therapeutic approach in $\mathrm{MG}$ is based on proinflammatory cytokine activity inhibition. IL-6, generated by different cells, including monocytes and B cells, induces the switching from suppressive regulatory $\mathrm{T}$ cells (Treg) to pathogenic $\mathrm{T}$ helper 17 (Th17) cells and promotes B cell differentiation into antibody-secreting cells. Equilibrium between Treg and Th17 cells is perturbed in EAMG upregulating Th17 subtype [51]. Blockade of IL-6 in EAMG murine model reduced B cells and anti-AChR Ab levels [51].

Tocilizumab, a recombinant humanized anti-IL6 receptor $\mathrm{Ab}$, was approved for RA, Castelman's disease and juvenile idiopathic arthritis treatment, and it was beneficial in two cases of MG severe and refractory to rituximab [52]. No TEAEs were reported; however, perforated diverticulitis occurred in patients with RA receiving the drug [53]. Tocilizumab has been used in severe cases of COVID-19: one patient with MG, receiving tocilizumab after a myasthenic crisis, was extubated without myasthenic exacerbation [54]. As a result, tocilizumab may be considered a suitable alternative of therapy in refractory MG, especially in those cases overlapping with COVID-19 disease. Clinical trials are necessary to evaluate the effectiveness and safety of this drug. A summary of emerging MG therapy characteristics is reported below in Table 1.

\section{The other side of immunotherapy}

MG can be worsened or, more often triggered, by medications acting at different levels on the immune system. In these cases, toxicity is not MG-specific, as these agents may be associated with a variety of immune-related adverse events (irAEs), MG is mostly associated with anti-AChR Abs and, typically, patients develop MG within weeks or months after treatment and may recover after treatment withdrawal. Up to $7 \%$ of patients treated with d-penicillamine develop MG, mostly with mild generalized or purely ocular manifestations. The effect on the immune system is not clear, but the observation that MG occurs more commonly during d-penicillamine treatment for rheumatoid arthritis than for Wilson's disease suggests that a genetic background predisposing to autoimmunity may play a role [55].

MG onset or worsening has been reported during treatment with INF- $\alpha$ in at least 40 patients. Such a complication was more common among subjected treated for chronic $\mathrm{C}$ hepatitis than in those with cancer. MG occurred in 4 patients receiving
INF- $\beta$, mostly during treatment for multiple sclerosis [56]. The use of TNFis has been associated with a number of irAEs, mainly cutaneous vasculitis, lupus-like syndrome, SLE, and interstitial lung disease. Autoimmunity may be induced by a cytokine shift, as TNFis suppresses T helper Th1 responses and favors Th2 cells and type I interferons [57]. Development of MG has been associated with etanercept [58], adalimumab [10], and etanercept plus ustekinumab (anti-interleukin12/23) [9]. In a pilot trial on etanercept in steroiddependent MG pts, 8 of 11 patients completed the study and two were withdrawn due to a severe MG worsening [8].

In recent years, cancer treatment with immune checkpoint inhibitors has gained widespread interest given its potential to induce a variety of irAEs, including MG. The mechanisms underlying these unwanted effects and the characteristics of the associated disease will be discussed in more detail.

\section{Immune checkpoint inhibitors and associated irAEs}

Immune checkpoints (ICPs) are inhibitory molecules, expressed on $\mathrm{T}$ cell surface, that modulate the immune system, maintaining self-tolerance and preventing host tissue damage by uncontrolled responses to foreign or self-antigens. Through overexpression of ICPs, cancer cells elude T cell-mediated destruction. CTLA-4 and PD-1 are the best characterized ICPs and the main target of cancer immunotherapy. CTLA-4 is a homolog of CD28 (the costimulatory receptor on T cells) that binds CD80 and CD86 on dendritic cells with higher affinity than $\mathrm{CD} 28$, substantially reducing $\mathrm{T}$ cell activation $[59,60]$ (Fig. 1a). CTLA-4 is constitutively expressed on Tregulatory (Treg) cells which play a crucial role in immune homeostasis [60].

PD-1 is expressed on activated T and B cells, natural killer cells, antigen-presenting cells, myeloid cells, and intratumoral Tregs [61]. Two PD-1 ligands have been identified (PD-L1 and -L2); of these, PD-L1 is expressed not only on immune cells, but also on epithelial cells and cancer cells [60]. Upon ligation, PD-1 acts downstream of T cell receptor reducing the expression of cytokines and transcription factors required for T cell function [59] (Fig. 1c). It is worth noticing that, while PD-1 is expressed on activated T cells in peripheral tissues, CTLA-4 exerts its effects on T lymphocytes primed in lymphnodes irrespective of the antigen specificity [59]. An additional mechanism of $\mathrm{T}$ cell immunosuppression is represented by the presence of activated FoXP3+Tregs within the lymphoid organs and the tumor microenvironment (Fig. 1e).

ICP inhibitors (ICI) are humanized monoclonal Abs targeting CTLA-4 (nivolumab), PD-1 (nivolumab, pembrolizumab) and PD-L1 (tremelizumab, atezolizumab, avelumab, durvalumab). Initially approved for melanoma, non-small cell lung carcinoma, and renal cell carcinoma, these agents have lately become available for a broad range of tumors and have dramatically changed the long-term prognosis 
Table 1 Characteristics of emerging drugs for MG

\begin{tabular}{|c|c|c|c|c|c|}
\hline Drug & Target & Mechanism of action & Administration & Mg study status & Main side effects \\
\hline Eculizumab & $\mathrm{C} 5$ & C5 inhibition & IV & $\begin{array}{l}\text { Approved (USA, Europe, } \\
\text { Japan) }\end{array}$ & $\begin{array}{l}\text { Infection by encapsulated bacteria, } \\
\text { headache, nasopharyngitis }\end{array}$ \\
\hline Ravulizumab & $\mathrm{C} 5$ & High-affinity C5 inhibition & IV & $\begin{array}{l}\text { Phase III clinical trial } \\
\text { ongoing }\end{array}$ & Similar to eculizumab \\
\hline Zilucoplan & $\mathrm{C} 5$ & C5 inhibition & $\mathrm{SC}$ & $\begin{array}{l}\text { Phase III clinical trial } \\
\text { ongoing }\end{array}$ & $\begin{array}{l}\text { Potential risk of infection by } \\
\text { encapsulated bacteria }\end{array}$ \\
\hline Efgartigimod & FcRn & $\begin{array}{l}\text { Prevention of FcRn-mediated } \operatorname{IgG} \\
\text { recycling }\end{array}$ & IV & $\begin{array}{l}\text { Phase III clinical trial } \\
\text { ongoing }\end{array}$ & $\begin{array}{l}\text { Headache, reduction of monocyte } \\
\text { count }\end{array}$ \\
\hline Rozanolixizumab & FcRn & $\begin{array}{l}\text { Prevention of FcRn-mediated IgG } \\
\text { recycling }\end{array}$ & $\mathrm{SC}$ & $\begin{array}{l}\text { Phase III clinical trial } \\
\text { ongoing }\end{array}$ & Headache \\
\hline $\begin{array}{l}\text { Nipocalimab } \\
\text { (M281) }\end{array}$ & FcRn & $\begin{array}{l}\text { Prevention of FcRn-mediated IgG } \\
\text { recycling }\end{array}$ & IV & $\begin{array}{l}\text { Phase II clinical trial } \\
\text { completed, results not } \\
\text { published }\end{array}$ & Potential risk of infection \\
\hline Rituximab & $\begin{array}{l}\text { CD-20 B } \\
\text { cells }\end{array}$ & $\mathrm{B}$ cells depletion & IV & $\begin{array}{l}\text { Phase III clinical trial } \\
\text { ongoing }\end{array}$ & $\begin{array}{l}\text { Infections, allergic infusion } \\
\text { reaction, reactivation of herpes } \\
\text { zoster, PML }\end{array}$ \\
\hline Belimumab & $\begin{array}{l}\text { BAFF } \\
\text { factor }\end{array}$ & $\begin{array}{l}\text { Prevention of B cells } \\
\text { differentiation into } \\
\text { antibody-secreting cells }\end{array}$ & IV & $\begin{array}{l}\text { Phase II clinical trial } \\
\text { completed }\end{array}$ & $\begin{array}{l}\text { Flu, nausea, one case of } \\
\text { sepsis-induced death }\end{array}$ \\
\hline Bortezomib & Proteasome & $\begin{array}{l}\text { Plasma cells apoptosis by } \\
\text { inhibition of proteasome }\end{array}$ & $\mathrm{SC}$ & $\begin{array}{l}\text { Phase II clinical trial } \\
\text { completed }\end{array}$ & Sensorimotor polyneuropathy \\
\hline Etanercept & $\mathrm{TNF} \alpha$ & $\mathrm{TNF} \alpha$ inhibition & $\mathrm{SC}$ & No & $\begin{array}{l}\text { Infection and autoimmune } \\
\text { phenomena (including } \mathrm{MG} \\
\text { onset/worsening) }\end{array}$ \\
\hline Infliximab & $\mathrm{TNF} \alpha$ & $\mathrm{TNF} \alpha$ inhibition & IV & No & Similar to etanercept \\
\hline Adalimumab & $\mathrm{TNF} \alpha$ & $\mathrm{TNF} \alpha$ inhibition & $\mathrm{SC}$ & No & Similar to etanercept \\
\hline Tocilizumab & $\begin{array}{l}\text { IL-6 } \\
\quad \text { receptor }\end{array}$ & $\begin{array}{l}\text { Blocking of a switch from } \\
\text { suppressive Treg to pathogenic } \\
\text { Th17 cells }\end{array}$ & IV & No & Good safety \\
\hline
\end{tabular}

$M G$ myasthenia gravis, $C 5$ fragment 5 of complement, $I V$ intravenous, $S C$ subcutaneous, $F c R n$ neonatal fragment crystallizable receptor, $I g G$ immunoglobulin type G, $P M L$ progressive multifocal leukoencephalopathy, BAFF B cell-activating factor, TNF tumor necrosis factor, IL-6 interleukin-6, Treg cells suppressive regulatory T cells, Th17 cells T helper 17 cells

of metastatic cancer. Clinical effects rely on their ability to overcome the ICP overexpression in/around tumor tissue, allowing an effective anti-tumor response (Fig. 1b, d, f). Not surprisingly, unleashing the immune system occurs at the expense of tolerance breakdown [60]. Moreover, considering the ICP major targets, it is not surprising that irAEs occur more frequently with anti-CTLA-4 than with anti-PD-1/-PD-L1 treatment [62] and their frequency is higher (around 90\%) in patients receiving ICI combination therapy [62].

Frequent irAEs are dermatologic, intestinal, hepatic, and endocrine diseases of mild to moderate severity (CTCAE Common Terminology Criteria for Adverse Events grades $1-2)$. The only neurologic disorder in this group is sensorimotor neuropathy. Severe or life-threatening organ-specific irAEs, as cardiac, hematologic, rheumatic, and respiratory diseases, of any CTCAE grade, are classified as rare or infrequent. Neurological irAEs, including MG, are part of this group [63]. In a review including 9208 patients exposed to ICI treatment, the rate of any grade neurological irAEs was $3.8 \%$ with anti-CTLA4 mAbs, $6.1 \%$ for anti-PD1, and $12 \%$ with combination therapy. Most of these consisted of mild unspecific symptoms, like headache, dysgeusia, and dizziness. High-grade irAEs had an incidence below $1 \%$ for all types of treatment [64].

\section{MG complicating treatment with immune checkpoint inhibitors}

MG triggered by ICI treatment was first described in 2015 in two patients treated with ipilimumab for metastatic melanoma [65]. In subsequent studies, MG was found to be a rare, but a potentially fatal complication, with an estimated frequency, among patients treated with PD-1 inhibitors, ranging from $0.12-0.2 \%[66,67]$. Around $75 \%$ of these patients were positive for AChR Abs. A single patient with MuSK Abs has been reported so far [11]. From our literature review, de novo MG during ICI treatment was diagnosed so far in 9 patients treated with anti-CTLA-4, in 50 receiving PD1 or PD1-L inhibitors and in 9 under combined therapy. MG exacerbation 

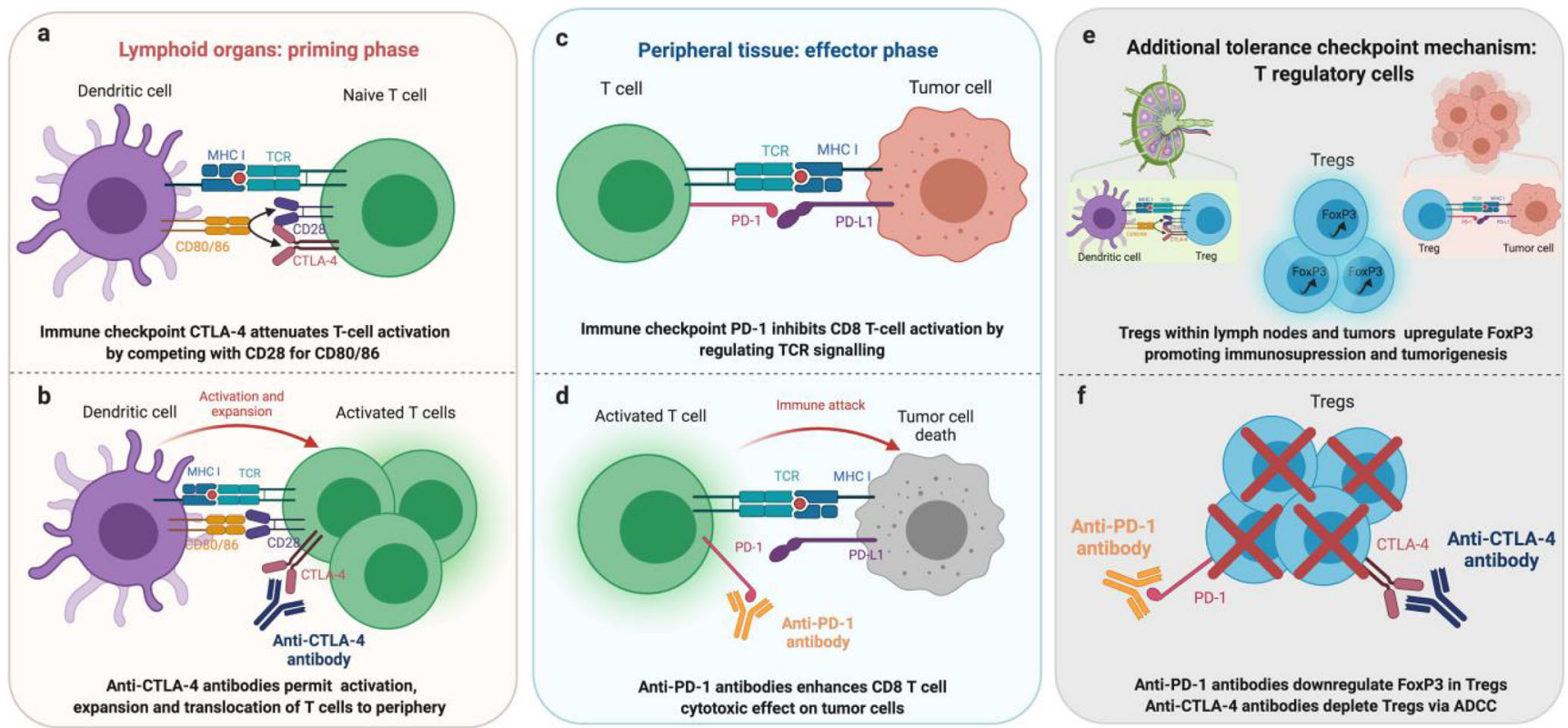

Fig. 1 Mechanism of CTLA-4 T cell inhibition during priming in secondary and tertiary lymph nodes (a). CTLA-4 blockade enhances CD28 co-stimulation and thus T cell activation (b). PD-1 is expressed by tissueresident CD8 T lymphocytes and modulate TCR favoring their exhaustion (c). PD-1 blockade reverses exhaustion signals by blocking PD-1PD-L1 interactions (d). Within the lymphoid organs and the tumor microenvironment, Tregs are activated and upregulate FoxP3 expression (e).

by anti-PD-1 was reported in 12 cases. These data are shown in Fig. 2a.

In $51 \%$ of patients, MG was the only irAE reported. Otherwise, it was frequently associated with myositis (particularly necrotizing myopathy, but also polymyositis, dermatomyositis, and unspecific myopathy), and, less commonly, with myocarditis or a combination of myositis and myocarditis. In a low proportion of cases, all these diseases were concomitant with polyneuropathy. Figure $2 \mathrm{~b}$ illustrates these findings.

The co-occurrence of MG and myositis, with or without myocarditis, is rare and, apart from ICI-treated patients, had been reported mostly in patients with thymoma [68, 69]. Recently, treatment with ICP inhibitors has been proposed for advanced thymoma and thymic carcinoma and is currently being evaluated in phase 2 trials. However, all these diseases as severe or fatal irAEs were reported during anti-PD1 treatment in these cases $[70,71]$. MG onset or deterioration generally occurred in the early phase of ICI treatment. Symptom severity was variable, with around $10 \%$ of cases with ocular or mild generalized MG and the great majority of patients rapidly progressing to moderate-severe symptoms [11, 72].

Mortality is around $25-30 \%$, mostly due to MG crises, although myocarditis, when associated, is frequently fatal. Therefore, early diagnosis, close clinical monitoring, and
Treg depletion caused by anti-CTLA-4 and anti-PD-1 mAbs is due to $\mathrm{ADCC}$ and Treg survival reduction, respectively (f). The figure was done using Biorender.com. ADCC antibody-dependent cellular cytotoxicity, CTLA-4 cytotoxic T lymphocyte antigen 4, FoxP3 forkhead, box P3; mAbs monoclonal antibodies, PD-1 programmed death cell protein 1 , TCR T cell receptor, Tregs T regulatory cells

prompt treatment are crucial. Most patients improved with aggressive treatment that included high-dose steroids, PLEX, or IVIg $[11,63,73]$. Rituximab can be used in patients unresponsive to first-line therapy [63].

In most cases, ICI treatment was discontinued after MG onset. Re-challenge with ICIs had mixed outcomes with some patients experiencing recurrent irAEs and others tolerating treatment without complications [72].

\section{Conclusion}

In the last decade, the need for more effective treatments, led to an increased use of biologics and to the development of more targeted therapies. RTX is a valid strategy in the therapy of MuSK Abs+ MG patients, and it could be suggested as a steroid-sparing agent in this form. Its effect is still unclear in AChR Abs + MG. Complement inhibitors, considering their greater targeting action, may represent one of the largest steps towards in immunotherapy. Eculizumab and ravulizumab can represent an approach to treat AChR-related refractory MG. FcRn inhibitors could be considered in short-term immunotherapy overcoming the limitations of PLEX and IVIg, including short duration of efficacy, repetitive doses, and a large volume of infusion.

Considering that FcRn inhibitors can induce a prolonged IgG depletion, they are a promising candidate for a first-line in 
a

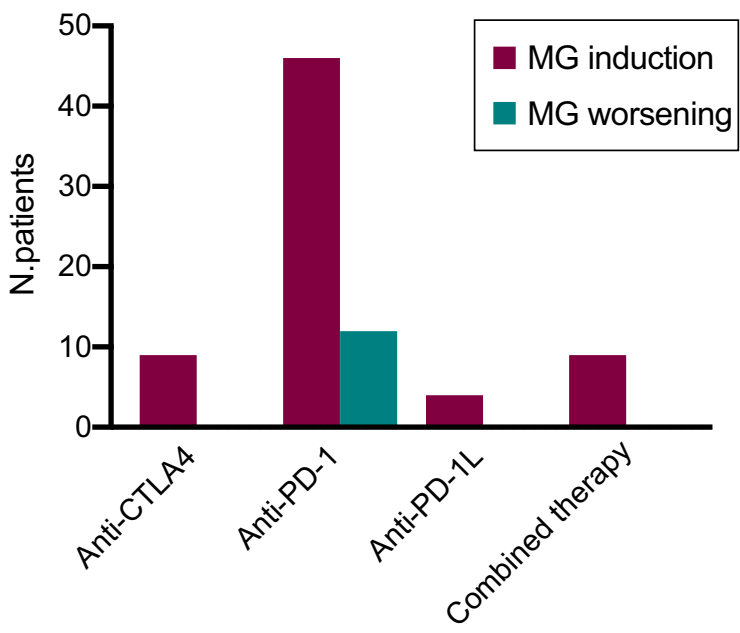

b

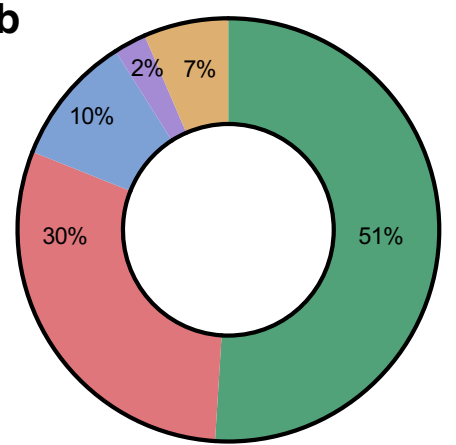

only MG

MG+myositis

$\square$ MG+myocarditis

$\square$ MG+myositis +myocarditis

$\square$ MG+myositis +myocarditis +polyneuropathy

Fig. 2 a, b Seventy-nine cases of ICI- related MG have been described so far (a). The majority of these cases (85\%) are triggered by ICI and, in particular, by anti-PD-1 drugs (62\%). Half of the ICI-related MG cases has been described in association with another immune-mediated disease (b). ICI immune-checkpoint inhibitors, MG myasthenia gravis, PD-1 programming death 1. 2a. Frequency of MG during ICI treatment with different agents. MG and associated diseases during ICI treatment

long-term immunosuppression therapy. Nevertheless, high cost, potential adverse events during chronic therapy, and production of anti-drug antibodies, represent some limitations of these new biologics. The future purpose is to discover unknown long-term effects of these drugs and to identify biomarkers of severity of disease to predict therapeutic response.

These advances fostered research work on the disease pathophysiology, on the mechanisms involved in the breakdown of immune tolerance. At the same time, from a better understanding of the immune tolerance, checkpoints stemmed the very effective cancer immunotherapy. As expected, the unlash of the immune system resulted in autoimmune adverse events. Clinicians must be aware of possible complications related to the use of biologics, and counterbalance benefits and dangers in individual patients.

Author's contributions All authors contributed equally to the paper.

Funding No funding was received for conducting this study.

\section{Declarations}

Conflict of interest The authors have no relevant financial or nonfinancial interests to disclose.

Ethical approval None.

Informed consent None.

Abbreviations $M G$, Myasthenia gravis; $N M J$, Neuromuscular junction; $g M G$, Generalized myasthenia gravis; $A C h R$, Acetylcholine receptor; $M u S K$, Muscle-specific kinase; $L R P 4$, Lipoprotein-related peptide 4; $P L E X$, Plasma exchange; IVIg, Intravenous immunoglobulins; $F c R n, \mathrm{Fc}$ neonatal receptor; CTLA-4, Cytotoxic T lymphocyte-associated protein 4; $P D$-1, Programmed cell death protein 1; $A b$, Antibody; $M A C$, Membrane attack complex; FDA, US Food and Drug Administration; $P N H$, Paroxysmal nocturnal hemoglobinuria; aHUS, Atypical hemolytic uremic syndrome; NMOSD, Neuromyelitis optica spectrum disorder; $M G F A$, Myasthenia Gravis Foundation of America; $Q M G$, Quantitative myasthenia gravis score; $S C$, Subcutaneous; $M G-A D L$, Myasthenia gravis activities of daily living profile; $Q M G$, Myasthenia Gravis Composite; $M G-Q o L 15 r$, Myasthenia Gravis Quality of Life 15-item; TEAEs, Treatment-emergent adverse events; $S A D$, Single ascending dose; $M A D$, Multiple ascending doses; $M H C$, Major histocompatibility complex; $B A F F$, B cell-activating factor; $R T X$, Rituximab; $R A$, Rheumatoid arthritis; SLE, Systemic lupus erythematosus; JCV, John Cunningham virus; BLys, B Lymphocyte stimulator; $E A M G$, Experimental autoimmune MG; $T N F$, Tumor necrosis factor; $I L-6$, Interleukin; IFN, Interferon; TNFis, TNF inhibitors; Treg, Suppressive regulatory $\mathrm{T}$ cells; Th17, T helper 17; irAEs, Immune-related adverse events; $I C P$, Immune checkpoints; $I C I$, Immune checkpoints inhibitors; CTCAE, Common Terminology Criteria for Adverse Events

\section{References}

1. Evoli A, Antonini G, Antozzi C, DiMuzio A, Habetswallner F, Iani C, Inghilleri M, Liguori R, Mantegazza R, Massa R, Pegoraro E, Ricciardi R, Rodolico C (2019) Italian recommendations for the diagnosis and treatment of myasthenia gravis. Neurol Sci 40(6):1111-1124. https://doi.org/10.1007/ s10072-019-03746-1

2. Mantegazza R, Antozzi C (2018) When myasthenia gravis is deemed refractory: clinical signposts and treatment strategies. Ther Adv Neurol Disord 11:1756285617749134. https://doi.org/ $10.1177 / 1756285617749134$.

3. Dmytrijuk A, Robie-Suh K, Cohen MH, Rieves D, Weiss K, Pazdur R (2008) FDA report: eculizumab (Soliris) for the treatment of patients with paroxysmal nocturnal hemoglobinuria. Oncologist 13(9):993-1000. https://doi.org/10.1634/theoncologist.2008-0086

4. Legendre CM, Licht C, Muus P, Greenbaum LA, Babu S, Bedrosian C et al (2013) Terminal complement inhibitor eculizumab in atypical hemolytic-uremic syndrome. N Engl $\mathrm{J}$ Med 368(23):2169-2181

5. FDA (2020) FDA approves first treatment for neuromyelitis optica spectrum disorder, a rare autoimmune disease of the central nervous system. Available online at: http://www.fda.gov/news-events/ press-announcements/fda-approves-first-treatment-neuromyelitisoptica-spectrum-disorderrare-autoimmune-disease-central. Accessed 21 March 2020

6. Alshaiki F, Obaid E, Almuallim A, Taha R, El-Haddad H, Almoallim H (2018) Outcomes of rituximab therapy in refractory 
lupus: a meta-analysis. Eur J Rheumatol 5:118-126. https://doi.org/ 10.5152/eurjrheum.2018.1709632.

7. Huang Z, Wu Y, Zhou X, Xu J, Zhu W, Shu Y et al (2014) Efficacy of therapy with bortezomib in solid tumors: a review based on 32 clinical trials. Future Oncol 10(10):1795-1807

8. Rowin J (2008) Etanercept treatment in myasthenia gravis. Ann N Y Acad Sci 1132:300-304. https://doi.org/10.1196/annals.1405. 028

9. Nicocia G, Bonanno C, Lupica A, Toscano A, Rodolico C (2020) Myasthenia gravis after etanercept and ustekinumab treatment for psoriatic arthritis: a case report. Neuromuscul Disord 30(3):246249. https://doi.org/10.1016/j.nmd.2020.01.001.

10. Pelechas E, Memi T, Markatseli TE, Voulgari PV, Drosos AA (2020) Adalimumab-induced myasthenia gravis: case-based review. Rheumatol Int 40(11):1891-1894. https://doi.org/10.1007/ s00296-020-04587-4

11. Huang YT, Chen YP, Lin WC, Su WC, Sun YT (2020) Immune checkpoint inhibitor-induced myasthenia gravis. Front Neurol 11: 634. https://doi.org/10.3389/fneur.2020.00634

12. Albazli K, Kaminski HJ, Howard JF Jr (2020) Complement inhibitor therapy for myasthenia gravis. Front Immunol 11:917. https:// doi.org/10.3389/fimmu.2020.00917

13. Wijnsma KL, Ter Heine R, Moes DJAR, Langemeijer S, Schols SEM, Volokhina EB, van den Heuvel LP, Wetzels JFM, van de Kar NCAJ, Brüggemann RJ (2019) Pharmacology, pharmacokinetics and pharmacodynamics of eculizumab, and possibilities for an individualized approach to eculizumab. Clin Pharmacokinet 58(7): 859-874. https://doi.org/10.1007/s40262-019-00742-8.

14. FDA Approves soliris to treat generalized myasthenia gravis. Muscular Dystrophy Association. (2017) Available online at: https://www.mda.org/press-releases/fda-approves-soliris-treatgeneralized-myasthenia-gravis. Accessed 21 March 2020

15. Alexion Europe SAS. Soliris (eculizumab): summary of product characteristics. 2017. [cited 2020 Mar 30]. Available from: http:// www.ema.europa.eu/docs/en_GB/document_library/EPAR_ Product Information/human/000791/WC500054208.pdf

16. Howard JF, Utsugisawa K, Benatar M et al (2017) Safety and efficacy of eculizumab in anti-acetylcholine receptor antibody-positive refractory generalised myasthenia gravis (REGAIN): a phase 3, randomised, double-blind, placebo-controlled, multicentre study. Lancet Neurol 16(12):976-986. https://doi.org/10.1016/S14744422(17)30369-1

17. Muppidi S, Utsugisawa K, Benatar M et al (2019) Long-term safety and efficacy of eculizumab in generalized myasthenia gravis. Muscle Nerve 60:14-24

18. De Latour RP, Brodsky RA, Ortiz S et al (2018) Ravulizumab (ALXN1210) versus eculizumab in adults with paroxysmal nocturnal hemoglobinuria: pharmacokinetics and pharmacodynamics observed in two phase 3 randomized, multicenter studies [abstract no. 626]. Blood. 132

19. Howard JF Jr, Nowak RJ, Wolfe GI et al (2020) Clinical effects of the self-administered subcutaneous complement inhibitor zilucoplan in patients with moderate to severe generalized myasthenia gravis: results of a phase 2 randomized, double-blind, placebocontrolled, multicenter clinical trial. JAMA Neurol 77(5):582-592. https://doi.org/10.1001/jamaneurol.2019.5125

20. Roopenian DC, Akilesh S (2007) FcRn: the neonatal Fc receptor comes of age. Nat Rev Immunol 7(9):715-725. https://doi.org/10. 1038/nri2155

21. Ulrichts P, Guglietta A, Dreier T, van Bragt T, Hanssens V, Hofman E, Vankerckhoven B, Verheesen P, Ongenae N, Lykhopiy V, Enriquez FJ, Cho J, Ober RJ, Ward ES, de Haard H, Leupin N (2018) Neonatal Fc receptor antagonist efgartigimod safely and sustainably reduces IgGs in humans. J Clin Invest 128(10):4372-4386. https://doi.org/10.1172/JCI97911
22. Howard JF Jr, Bril V, Burns TM, Mantegazza R, Bilinska M, Szczudlik A, Beydoun S, Garrido FJRR, Piehl F, Rottoli M, Van Damme P, Vu T, Evoli A, Freimer M, Mozaffar T, Ward ES, Dreier T, Ulrichts P, Verschueren K, Guglietta A, de Haard H, Leupin N, Verschuuren JJGM (2019) Efgartigimod MG Study Group. Randomized phase 2 study of FcRn antagonist efgartigimod in generalized myasthenia gravis. Neurology. 92(23):e2661-e2673. https://doi.org/10.1212/WNL.0000000000007600.

23. An efficacy and safety study of ARGX-113 in patients with myasthenia gravis who have generalized muscle weakness Available online at: https://clinicaltrials.gov/ct2/show/NCT03669588. Accessed 22 March 2020

24. Bril V, Benatar M, Brock M et al (2019) Proof-of-concept and safety of the anti-FcRn antibody rozanolixizumab in patients with moderate-to-severe generalized myasthenia gravis (GMG): a phase 2a study. American Academy of Neuology Annual Meeting, Philadelphia, PA 92 (Suppl 15)

25. Ling LE, Hillson JL, Tiessen RG, Bosje T, van Iersel MP, Nix DJ et al (2019) M281, an anti-FcRn antibody: pharmacodynamics, pharmacokinetics, and safety across the full range of $\mathrm{IgG}$ reduction in a first-in-human study. Clin Pharmacol Ther 105:1031-1039. https://doi.org/10.1002/cpt.1276

26. Momenta. Pharmaceuticals, Inc (2018) A study to evaluate the safety, tolerability, efficacy, pharmacokinetics and pharmacodynamics of M281 administered to adults with generalized myasthenia gravis. Clinicaltrials.gov. Available online at: https:// clinicaltrials.gov/ct2/show/NCT03772587?term=M281\&rank=5

27. Beecher G, Putko BN, Wagner AN, Siddiqi ZA (2019) Therapies directed against $B$ cells and downstream effectors in generalized autoimmune myasthenia gravis: current status. Drugs. 79:353364. https://doi.org/10.1007/s40265-019-1065-0

28. Schneider P, MacKay F, Steiner V, Hofmann K, Bodmer JL, Holler $\mathrm{N}$ et al (1999) BAFF, a novel ligand of the tumor necrosis factor family, stimulates B cell growth. J Exp Med 189(11):1747-1756

29. Derer S, Kellner C, Berger S, Valerius T, Peipp M (2012) Fc engineering: design, expression, and functional characterization of antibody variants with improved effector function. Methods Mol Biol 907:519-536. https://doi.org/10.1007/978-1-61779-974-7_30

30. US Food and Drug Administration. Rituxan prescribing information. https://www.accessdata.fda.gov/drugsatfda_docs/label/2018/ 103705s5450lbl.pdf. Accessed 22 Nov 2019

31. Lebrun C, Bourg V, Tieulie N, Thomas P (2009) Successful treatment of refractory generalized myasthenia gravis with rituximab. Eur J Neurol 16(2):246-250

32. Hehir MK, Hobson-Webb LD, Benatar M, Barnett C, Silvestri NJ, Howard JF Jr, Howard D, Visser A, Crum BA, Nowak R, Beekman R, Kumar A, Ruzhansky K, Chen IA, Pulley MT, LaBoy SM, Fellman MA, Greene SM, Pasnoor M, Burns TM (2017) Rituximab as treatment for anti-MuSK myasthenia gravis: multicenter blinded prospective review. Neurology. 89(10):1069-1077. https://doi.org/10.1212/WNL.0000000000004341

33. Tandan R, Hehir MK 2nd, Waheed W, Howard DB (2017) Rituximab treatment of myasthenia gravis: a systematic review. Muscle Nerve 56(2):185-196. https://doi.org/10.1002/mus.25597

34. Di Stefano V, Lupica A, Rispoli MG, Di Muzio A, Brighina F, Rodolico C (2020) Rituximab in AChR subtype of myasthenia gravis: systematic review. J Neurol Neurosurg Psychiatry 91(4): 392-395. https://doi.org/10.1136/jnnp-2019-322606.

35. Brauner S, Eriksson-Dufva A, Hietala MA, Frisell T, Press R, Piehl F (2020) Comparison between rituximab treatment for new-onset generalized myasthenia gravis and refractory generalized myasthenia gravis. JAMA Neurol 77(8):974-981. https://doi.org/10.1001/ jamaneurol.2020.0851

36. Choi K, Hong YH, Ahn SH, Baek SH, Kim JS, Shin JY, Sung JJ (2019) Repeated low-dose rituximab treatment based on the assessment of circulating $\mathrm{B}$ cells in patients with refractory myasthenia 
gravis. Ther Adv Neurol Disord 12:1756286419871187. https:// doi.org/10.1177/1756286419871187

37. Nowak RJ et al (2018) B cell targeted treatment in myasthenia gravis (BeatMG): a phase 2 trial of rituximab in myasthenia gravis. Neurology 90:e2182-e2194

38. Rodolico C, Bonanno C, Toscano A, Vita G (2020) MuSKassociated myasthenia gravis: clinical features and management. Front Neurol 11:660. https://doi.org/10.3389/fneur.2020.00660.

39. Kanth KM, Solorzano GE, Goldman MD (2016) PML in a patient with myasthenia gravis treated with multiple immunosuppressing agents. Neurol Clin Pract 6:e17-e19

40. Waters MJ, Field D, Ravindran J (2019) Refractory myasthenia gravis successfully treated with ofatumumab. Muscle Nerve 60(6):E45-E47. https://doi.org/10.1002/mus.26707

41. Russell A, Yaraskavitch M, Fok D, Chhibber S, Street L, Korngut L (2017) Obinutuzumab plus chlorambucil in a patient with severe myasthenia gravis and chronic lymphocytic leukemia. J Neuromuscul Dis 4(3):251-257. https://doi.org/10.3233/JND170211.

42. Sorensen PS, Lisby S, Grove R et al (2014) Safety and efficacy of ofatumumab in relapsing-remitting multiple sclerosis: a phase 2 study. Neurology 82:573-581

43. Hahn BH (2013) Belimumab for systemic lupus erythematosus. N Engl J Med 368(16):1528-1535

44. Kang SY, Kang CH, Lee KH (2016) B-cell-activating factor is elevated in serum of patients with myasthenia gravis. Muscle Nerve 54(6):1030-1033. https://doi.org/10.1002/mus.25162

45. Hewett K, Sanders DB, Grove RA, Broderick CL, Rudo TJ, Bassiri A, Zvartau-Hind M, Bril V (2018) BEL115123 Study Group. Randomized study of adjunctive belimumab in participants with generalized myasthenia gravis. Neurology. 90(16):e1425-e1434. https://doi.org/10.1212/WNL.0000000000005323.

46. Thibaudeau TA, Smith DM (2019) A practical review of proteasome pharmacology. Pharmacol Rev 71:170-197. https://doi.org/ 10.1124/pr.117.015370

47. Schneider-Gold C, Reinacher-Schick A, Ellrichmann G, Gold R (2017) Bortezomib in severe MuSK-antibody positive myasthenia gravis: first clinical experience. Ther Adv Neurol Disord 10(10): 339-341

48. Kohler S, Märschenz S, Grittner U, Alexander T, Hiepe F, Meisel A (2019) Bortezomib in antibody-mediated autoimmune diseases (TAVAB): study protocol for a unicentric, non-randomised, nonplacebo controlled trial. BMJ Open 9(1):e024523. https://doi.org/ 10.1136/bmjopen-2018-024523.

49. Ale A, Bruna J, Navarro X, Udina E (2014) Neurotoxicity induced by antineoplastic proteasome inhibitors. Neurotoxicology. 43:2835

50. Tüzün E, Huda R, Christadoss P (2011) Complement and cytokine based therapeutic strategies in myasthenia gravis. J Autoimmun 37(2):136-143. https://doi.org/10.1016/j.jaut.2011.05.006

51. Aricha R, Mizrachi K, Fuchs S, Souroujon MC (2011) Blocking of IL-6 suppresses experimental autoimmune myasthenia gravis. J Autoimmun 36(2):135-141. https://doi.org/10.1016/j.jaut.2010. 12.001

52. Jonsson DI, Pirskanen R, Piehl F (2017) Beneficial effect of tocilizumab in myasthenia gravis refractory to rituximab. Neuromuscul Disord 27(6):565-568. https://doi.org/10.1016/j.nmd.2017.03.007.

53. Iking-Konert $\mathrm{C}$, Von Hinuber U, Richter $\mathrm{C}$ et al (2016) ROUTINEa prospective, multicentre, non-interventional, observational study to evaluate the safety and effectiveness of intravenous tocilizumab for the treatment of active rheumatoid arthritis in daily practice in Germany. Rheumatology (Oxford) 55:624-635

54. Anand P, Slama MCC, Kaku M, Ong C, Cervantes-Arslanian AM, Zhou L, David WS, Guidon AC (2020) COVID-19 in patients with myasthenia gravis. Muscle Nerve 62(2):254-258. https://doi.org/ 10.1002/mus.26918.

55. Komal Kumar RN, Patil SA, Taly AB, Nirmala M, Sinha S, Arunodaya GR (2004) Effect of D-penicillamine on neuromuscular junction in patients with Wilson disease. Neurology 63:935-936

56. Krenn M, Grisold A, Wohlfarth P, Rath J, Cetin H, Koneczny I, Zimprich F (2020) Neuromuscular disorders induced by medical treatments. Front Mol Neurosci 13:156

57. Her M, Kavanaugh A (2016) Alterations in immune function with biologic therapies for autoimmune disease. J Allergy Clin Immunol 137:19-27

58. Fee DB, Kasarskis EJ (2009) Myasthenia gravis associated with etanercept therapy. Muscle Nerve 39:866-870

59. Soularue E, Lepage P, Colombel JF et al (2018) Enterocolitis due to immune checkpoint inhibitors: a systematic review. Gut 67:20562067

60. Sweis RF, Luke JJ (2017) Mechanistic and pharmacologic insights on immune checkpoint inhibitors. Pharmacol Res 120:1-9

61. Francisco LM, Sage PT, Sharpe AH (2010) The PD-1 pathway in tolerance and autoimmunity. Immunol Rev 236:219-242

62. Möhn N, Beutel G, Gutzmer R, Ivanyi P, Satzger I, Skripuletz T (2019) Neurological immune related adverse events associated with nivolumab, ipilimumab, and pembrolizumab therapy-review of the literature and future outlook. J Clin Med 8(11):1777. https://doi. org/10.3390/jcm8111777.

63. Majem M, Martínez GE, Martinez M et al (2020) SEOM clinical guideline for the management of immune related adverse events in patients treated with immune checkpoint inhibitors. Clin Transl Oncol 22:213-222

64. Cuzzubbo S, Javeri F, Tissier M et al (2017) Neurological adverse events associated with immune checkpoint inhibitors: review of the literature. Eur J Cancer 73:1-8

65. Johnson DB, Saranga-Perry V, Lavin PJM et al (2015) Myasthenia gravis induced by ipilimumab in patients with metastatic melanoma. J Clin Oncol 33:e122-e124

66. Suzuki S, Ishikawa N, Konoeda F et al (2017) Nivolumab-related myasthenia gravis with myositis and myocarditis in Japan. Neurology 89:1127-1134

67. Kao JC, Brickshawana A, Liewluck T (2018) Neuromuscular complications of programmed cell death-1 (PD-1) inhibitors. Curr Neurol Neurosci Rep 18:63

68. Kon T, Mori F, Tanji K, Miki Y, Kimura T, Wakabayashi K (2013) Giant cell polymyositis and myocarditis associated with myasthenia gravis and thymoma. Neuropathology 33:281-287

69. Garibaldi M, Fionda L, Vanoli F et al (2020) Muscle involvement in myasthenia gravis: expanding the clinical spectrum of myasthenia-myositis association from a large cohort of patients. Autoimmun Rev 19:102498

70. Konstantina T, Konstantinos R, Anastasios K et al (2019) Fatal adverse events in two thymoma patients treated with anti-PD-1 immune check point inhibitor and literature review. Lung Cancer 135:29-32

71. So H, Ikeguchi R, Kobayashi M, Suzuki M, Shimizu Y, Kitagawa K (2019) PD-1 inhibitor-associated severe myasthenia gravis with necrotizing myopathy and myocarditis. J Neurol Sci 399:97-100

72. Puwanant A, Isfort M, Lacomis D, Živković SA (2019) Clinical spectrum of neuromuscular complications after immune checkpoint inhibition. Neuromuscul Disord 29:127-133

73. Phillips GS, Wu J, Hellmann MD et al (2019) Treatment outcomes of immune-related cutaneous adverse events. J Clin Oncol 37: $2746-2758$

Publisher's note Springer Nature remains neutral with regard to jurisdictional claims in published maps and institutional affiliations. 